\title{
Electrochemical noise and impedance study of aluminium in weakly acid chloride solution
}

\author{
Carla Gouveia-Caridade $^{\mathrm{a}}$, M. Isabel S. Pereira ${ }^{\mathrm{b}, 1}$, Christopher M.A. Brett ${ }^{\mathrm{a}, *, 1}$ \\ a Departamento de Química, Universidade de Coimbra, 3004-535 Coimbra, Portugal \\ b Departamento de Química e Bioquímica, Universidade de Lisboa, 1749-016 Lisboa, Portugal
}

Received 25 February 2003; received in revised form 9 July 2003; accepted 22 September 2003

\begin{abstract}
The electrochemical noise (EN) characteristics of pure aluminium in unbuffered potassium chloride solution and with acetic acid/sodium acetate buffer at $\mathrm{pH} 5.4$ and 4.3 have been analysed to throw light on the influence of $\mathrm{pH}$ and of the presence of buffer at the aluminium surface on chloride ion-induced corrosion. Comparison has been made with results obtained by electrochemical impedance spectroscopy (EIS) and quantitative deductions made concerning the values of the noise resistance and the magnitude of the electrochemical impedance. Deviations between results obtained by the two experimental techniques are discussed.
\end{abstract}

(c) 2003 Elsevier Ltd. All rights reserved.

Keywords: Electrochemical noise; Electrochemical impedance spectroscopy; Aluminium; Corrosion; Chloride

\section{Introduction}

The electrochemical behaviour of aluminium and its alloys has been the subject of a large number of publications, since the naturally-formed oxide film can give excellent protection against corrosion, in addition to the advantages resulting from aluminium's low density. Amongst these, some studies have been undertaken in weakly acid solution in order to throw light on the effect of $\mathrm{pH}$ on the rate of the corrosion process [1-6], its inhibition by the addition of organic compounds [7,8], the influence of metal ions [9-11] and on the structure of the oxide layer and its semiconductor properties [2]. Electrochemical techniques employed have been mainly open circuit potential (OCP) measurements, polarisation curves and electrochemical impedance.

In acetate-buffered chloride solution, it was found that under cathodic polarisation the oxide film becomes permeable to protons in the presence of buffer [1]. Polarisation curves [2] and polarisation curves and impedance [3] were used to examine the corrosion behaviour in acetic acid/acetate

\footnotetext{
* Corresponding author. Tel.: +351-239-835295; fax: +351-239-835295.

E-mail address: brett@ci.uc.pt (C.M.A. Brett).

${ }^{1}$ ISE member.
}

solutions with a view to controlling the $\mathrm{pH}$ near the aluminium surface and gain insight into the corrosion mechanism. The study described in [4] used X-ray photoelectron spectroscopy (XPS) to investigate the influence of $\mathrm{pH}$ on the thickness and ion content of the aluminium oxide film in sodium chloride solution. Evidence was found for thicker oxide films at the extremes of oxide stability and the chloride content of the oxide film was maximum at $\mathrm{pH}$ 3.8. XPS and FT-IR were used to demonstrate that, under cathodic polarisation, carboxylic acids can adsorb weakly on the native oxide surface and can inhibit corrosion [5]. Acidic amino acids have also been shown to act as corrosion inhibitors of aluminium [6].

Electrochemical noise (EN) measurements have been widely used for the characterisation and monitoring of corrosion processes during the last 20 years [12]. Types of system which have been analysed are many, such as iron and aluminium and its alloys [13-15], coatings on metal substrates [16-19], erosion-corrosion [20] and microbiologically influenced corrosion [21,22]. The increased interest in the analysis of electrochemical noise is due to the low cost of the equipment, to the possibility of measurements in situ and to the lack of intrusiveness $[23,24]$.

The analysis of electrochemical noise data can be performed in both time and frequency domains. In the time 
domain the most interesting parameter is the noise resistance, $R_{\mathrm{n}}$, defined as the ratio of the standard deviations of potential and current noise $[25,26]$ which can be associated with the polarisation resistance, $R_{\mathrm{p}}$, although there is controversy concerning this [27]. In the frequency domain the spectral noise resistance, $R_{\mathrm{sn}}$, defined as the square-root of the ratio of power spectral densities (PSD) of potential and current fluctuations, can be compared with the magnitude of the electrochemical impedance at the same frequency $[17,26]$. Nevertheless, these parameters can only be obtained if potential and current noise are measured simultaneously, e.g. [28,29]. In recent years, the theory of electrochemical noise has been further developed to consider factors such as methods for trend removal [30], different transient shapes and electrode asymmetry [31-33], detection of localised and pitting corrosion [34,35], and partition of current fluctuations between different electrodes [36].

Electrochemical impedance spectroscopy (EIS) has been applied for over a decade for studying corrosion processes on aluminium and aluminium alloys, e.g. $[3,37,38]$. The technique is widely used and because of the similarities of impedance magnitude Bode plots with EN spectral noise plots, EIS can assume an important role in the analysis and comprehension of data from EN.

The objective of this paper is to examine the electrochemical noise behaviour of pure aluminium in chloride solution and in acetate-buffer solutions containing chloride ion in order to throw light on the influence of $\mathrm{pH}$ and of the presence of buffer at the aluminium surface on chloride ion-induced corrosion and to determine if electrochemical noise can be used as a good diagnostic method of any differences. The data analysis of EN is performed in time and frequency domains and the results are compared with those obtained by EIS. Open circuit potential variations with time were recorded to aid in explaining the mechanism of the processes occurring.

\section{Experimental}

\subsection{Aluminium electrodes}

Disc-shaped electrodes were made from pure aluminium (99.99\% purity, Goodfellow) cylindrical sections, diameter $0.70 \mathrm{~cm}$, in a tightly fitting Teflon sheath by compression, after gluing with silver epoxy to a brass rod which made the external, rear contact. The other end of the cylinder was machined flush with the Teflon to leave an exposed disc; all disc electrodes were of exactly the same surface area $\left(0.39 \mathrm{~cm}^{2}\right)$. In order to ensure a clean metal surface before any exposure to the corroding solutions, the electrodes were mechanically polished with 600 and 1200 grade silicon carbide papers. After this polishing procedure, the electrodes were cleaned with ethanol.

\subsection{Solutions}

Solutions of $0.1 \mathrm{M} \mathrm{KCl}$ were prepared with and without $0.1 \mathrm{M}$ acetate buffer. The $\mathrm{pH}$ values of the buffered solutions were 5.4 (the same as the unbuffered $0.1 \mathrm{M} \mathrm{KCl}$ solution) and 4.3. All solutions were prepared from analytical grade reagents and Millipore Milli-Q ultrapure water (resistivity $>18 \mathrm{M} \Omega \mathrm{cm}$ ), and not deaerated. Experiments were carried out at room temperature $\left(25 \pm 1{ }^{\circ} \mathrm{C}\right)$.

\subsection{Measurement methods}

\subsubsection{Electrochemical noise}

Electrochemical noise measurements were performed in a set-up with three identical aluminium electrodes using the experimental arrangement shown schematically in Fig. 1, within a Faraday cage. A $\mu$ AutoLab type 2 potentiostat (Ecochimie, The Netherlands) controlled by GPES 4.7 software was used for simultaneously recording the current and potential noise transients, shielded cables being used between the potentiostat and the electrodes. Instrumental noise was measured and shown to be smaller than that in the noise transients and there was no evidence of contributions from the line frequency.

After $1 \mathrm{~h}$ immersion of the electrodes the current and potential noise was sampled at a frequency $f_{\mathrm{s}}=100 \mathrm{~Hz}$ for $20.48 \mathrm{~s}$, a total of 2048 points. This procedure was repeated for longer immersion times up to a maximum time of $4 \mathrm{~h}$. Data analysis was performed in time and frequency domains with MicroCal Origin 6.0, using a Hanning window function.

\subsubsection{Electrochemical impedance spectroscopy}

Electrochemical impedance spectra were recorded with a Solartron 1250 Frequency Response Analyser together with a Solartron 1286 Electrochemical Interface (Solartron Analytical, UK), controlled by ZPlot software. The tests were

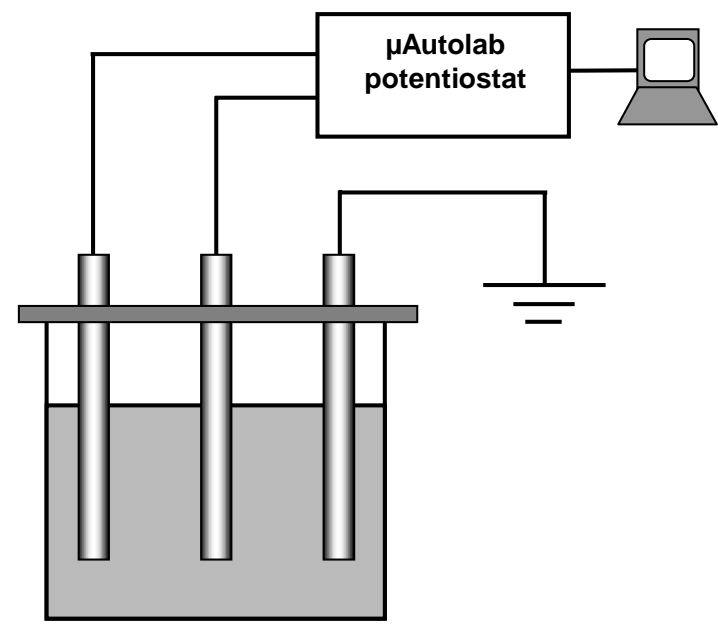

Fig. 1. Schematic experimental arrangement for electrochemical noise measurements. 
performed for different immersion times in a three-electrode one-compartment cell containing a working electrode of aluminium, a platinum foil auxiliary electrode and a saturated calomel electrode (SCE) as a reference. A sinusoidal perturbation of $10 \mathrm{mV} \mathrm{rms} \mathrm{was} \mathrm{applied} \mathrm{at} \mathrm{the} \mathrm{cell} \mathrm{rest} \mathrm{poten-}$ tial over the frequency range $65.5 \mathrm{kHz}-0.1 \mathrm{~Hz}$, in 10 steps per decade. Data fitting to equivalent circuits was performed with ZView software.

\section{Results and discussion}

\subsection{Open circuit potential}

In order to know when the potential of the aluminium electrodes becomes stable in the different solutions, the open circuit potential was first recorded in a three-electrode cell, as used in electrochemical impedance measurements, for a total of $4 \mathrm{~h}$ following immersion. Typical time variations of the open circuit potential are shown in Fig. 2 for the three types of solution. For all types of solution, immediately after immersion the potential of the aluminium electrode becomes more positive with the formation of aluminium oxide. After approximately $20 \mathrm{~min}$ the potential in the unbuffered solution begins to change to more negative values and stabilises after $60 \mathrm{~min}$ in the region of $-1.0 \mathrm{~V}$. This can probably be attributed to formation of oxychloro complexes at the electrode surface with consequent thinning of the oxide layer. During all these processes protons are consumed, so that the $\mathrm{pH}$ at the surface will become higher. In buffered solution, this $\mathrm{pH}$ increase will be much less and the presence of acetate ions and acetic acid molecules in the interfacial region will block the greater effects of the aggressive chloride ion. Nevertheless, already after 5-10 min oscillatory behaviour occurs in the presence of acetic acid/acetate for both $\mathrm{pH}$ val- ues employed, which can be attributed to cycles of localised formation/dissolution of aluminium oxide at the surface of the working electrode and that the corrosion is more uniform with only chloride ion (see following section for more discussion). It was found that the OCP is most constant with time in the buffer solution of $\mathrm{pH} 4.3$ with values of approximately $-0.660 \mathrm{~V}$ versus SCE. The difference in steady-state values of open circuit potential in buffered and unbuffered solution is reproducible and has been observed previously [2].

As a result of these experiments, the immersion time of the electrodes chosen for the EN and EIS experiments was from $1 \mathrm{~h}$ up to a maximum of $4 \mathrm{~h}$.

\subsection{Electrochemical noise analysis}

The potential and current noise were recorded simultaneously as described in the experimental section and the data were analysed in both time and frequency domains. Examples of typical raw data obtained are shown in Fig. 3. Concerning the potential transients, it can be seen that the high frequency noise is greatest in unbuffered chloride solution, less in $\mathrm{pH} 5.4$ buffered solution and relatively small in $\mathrm{pH}$ 4.3 buffered solution. The behaviour on the time scale of seconds is similar in both buffered solutions, although the variation in potential at $\mathrm{pH} 4.3$ is much larger-of the order of $4 \mathrm{mV}$ as opposed to $0.15 \mathrm{mV}$-suggesting differences in the corrosion mechanism. The current transients reflect these tendencies, being very similar for unbuffered and $\mathrm{pH}$ 5.4 buffered solutions, but with a much larger variation at $\mathrm{pH}$ 4.3. The latter tend to be asymmetric with a fast current rise followed by a slower recovery, which is characteristic of the formation of metastable pits [31]. Inspection of the surface of the electrodes after each type of experiment showed no difference between the two chloride-containing solutions

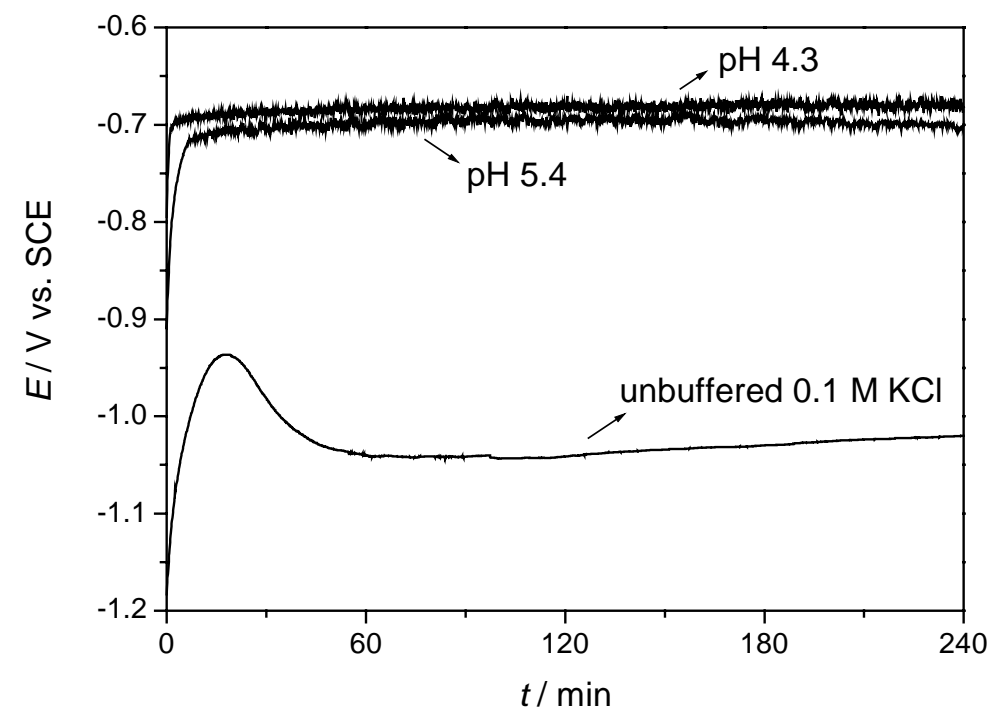

Fig. 2. Open circuit potential variation of aluminium in $0.1 \mathrm{M} \mathrm{KCl}$ and solutions of $0.1 \mathrm{M}$ acetate buffer/0.1 M KCl. 

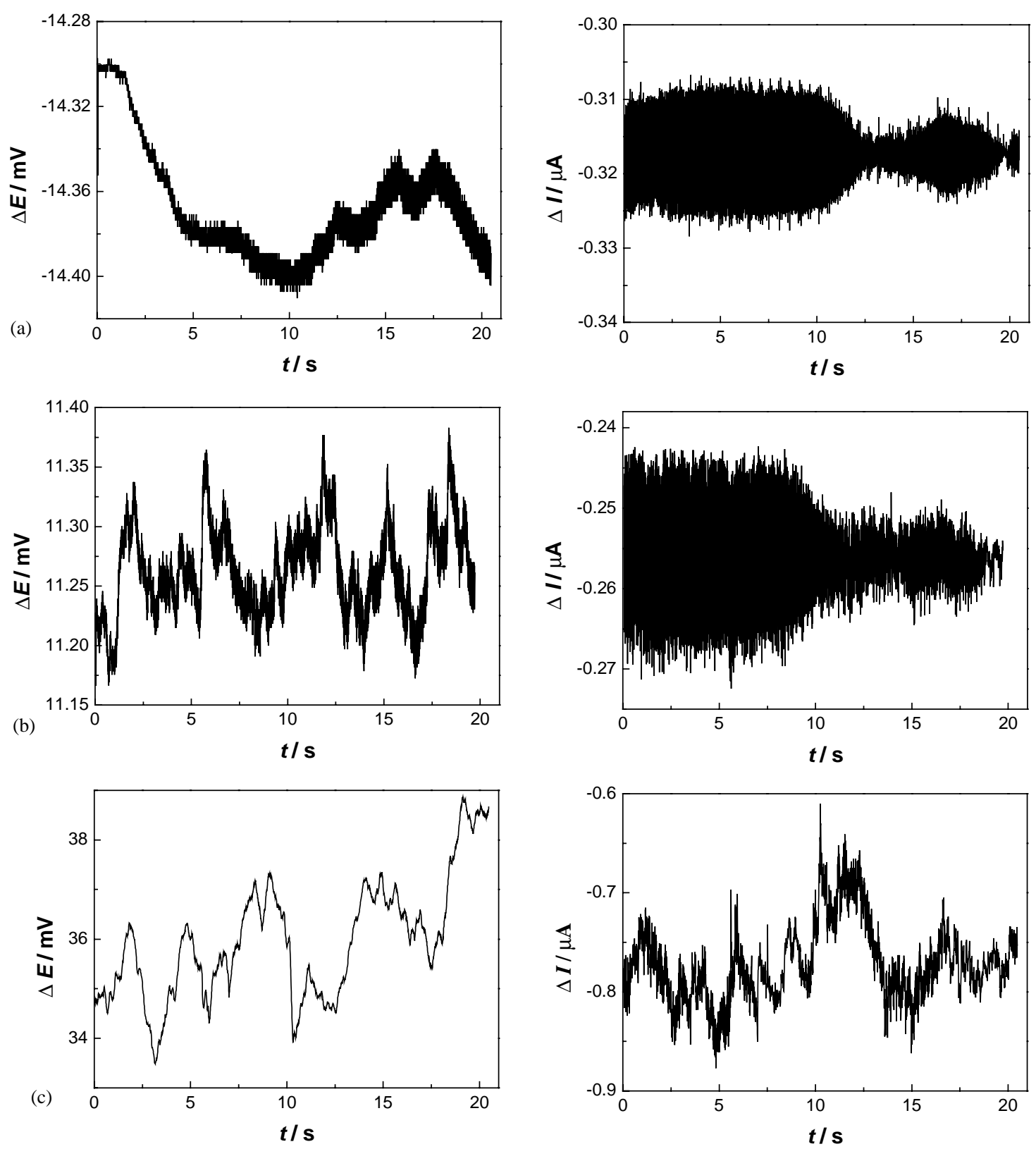

Fig. 3. Examples of potential and current noise records obtained after $1 \mathrm{~h}$ immersion in solutions of (a) $0.1 \mathrm{M} \mathrm{KCl}$; (b) $0.1 \mathrm{M}$ acetate buffer/0.1 M KCl solution, $\mathrm{pH} 5.4$; (c) $0.1 \mathrm{M}$ acetate buffer/0.1 $\mathrm{M} \mathrm{KCl}$ solution, $\mathrm{pH} 4.3$.

of the same $\mathrm{pH}$, buffered and unbuffered, but in the $\mathrm{pH} 4.3$ buffered chloride solution the surface showed a dark grey coloured roughened surface with tiny pits.

The noise resistance, $R_{\mathrm{n}}$, was determined in the time domain, as the ratio of the standard deviation of potential noise, $\sigma_{\mathrm{V}}$, to that of current noise, $\sigma_{\mathrm{I}},\left(R_{\mathrm{n}}=\sigma_{\mathrm{V}} / \sigma_{\mathrm{I}}\right)$. This parameter can be used to calculate the corrosion rate, assuming that is equivalent to polarisation resistance $R_{\mathrm{p}}$ [27,39-41]. This is an approximation, since strictly speaking it refers to corrosion in the absence of localised phenomena, which appears not to be the case in $\mathrm{pH} 4.3$ acetate-buffered solution, at least. The calculated parameters are summarized in
Table 1 and $R_{\mathrm{n}}$ is represented in Fig. 4 . It can be seen that $\sigma_{\mathrm{V}}$ and $\sigma_{\mathrm{I}}$ increase with a increase in the acetic acid/acetate ratio and with time. The calculated values for $R_{\mathrm{n}}$ are larger for the $\mathrm{pH} 4.3$ buffered solution which would imply a lower corrosion rate if there were uniform corrosion; however, an increase of corrosion rate is associated with the increasing of $\sigma_{\mathrm{I}}$ and a decrease of $\sigma_{\mathrm{V}}$ [42]. There is evidence from Fig. 3 of localised corrosion, as discussed above, i.e. the association of $\sigma_{\mathrm{V}}$ with the instability and localised corrosion of the surface, as can be seen in the open circuit potential transient, Fig. 2 and the data in Fig. 3. In this case the formation/dissolution of aluminium oxide and the presence of 
Table 1

Electrochemical noise data in the time domain obtained in $0.1 \mathrm{M} \mathrm{KCl}$ and in $0.1 \mathrm{M}$ acetate-buffered solution containing $0.1 \mathrm{M} \mathrm{KCl}$ at $\mathrm{pH} 5.4$ and $\mathrm{pH} 4.3$

\begin{tabular}{clll}
\hline $\begin{array}{l}\text { Immersion } \\
\text { time }(\mathrm{min})\end{array}$ & $0.1 \mathrm{M} \mathrm{KCl}$ & $\begin{array}{l}0.1 \mathrm{M} \mathrm{KCl} / \mathrm{pH} \\
5.4 \text { buffer }\end{array}$ & $\begin{array}{l}0.1 \mathrm{M} \mathrm{KCl} / \mathrm{pH} \\
4.3 \mathrm{buffer}\end{array}$ \\
\hline$\sigma_{\mathrm{V}}(\mathrm{V})$ & & & \\
60 & $4.94 \times 10^{-5}$ & $2.42 \times 10^{-5}$ & $1.19 \times 10^{-3}$ \\
120 & $5.42 \times 10^{-5}$ & $2.55 \times 10^{-5}$ & $8.79 \times 10^{-4}$ \\
180 & $7.99 \times 10^{-5}$ & $6.99 \times 10^{-5}$ & $1.68 \times 10^{-3}$ \\
240 & $2.10 \times 10^{-5}$ & $2.12 \times 10^{-5}$ & $1.05 \times 10^{-3}$ \\
$\sigma_{\mathrm{I}}\left(\mathrm{A} \mathrm{cm^{-2 } )}\right.$ & & & \\
60 & $2.28 \times 10^{-8}$ & $1.94 \times 10^{-8}$ & $1.03 \times 10^{-7}$ \\
120 & $3.15 \times 10^{-8}$ & $2.22 \times 10^{-8}$ & $7.41 \times 10^{-8}$ \\
180 & $3.54 \times 10^{-8}$ & $2.18 \times 10^{-8}$ & $1.03 \times 10^{-7}$ \\
240 & $4.18 \times 10^{-8}$ & $2.30 \times 10^{-8}$ & $6.77 \times 10^{-8}$ \\
$R_{\mathrm{n}}\left(\mathrm{k} \Omega \mathrm{cm}^{2}\right)$ & & & \\
60 & 2.09 & 1.24 & 11.6 \\
120 & 1.73 & 1.09 & 12.8 \\
180 & 2.25 & 3.15 & 15.8 \\
240 & 0.55 & 0.86 &
\end{tabular}

metastable pits on the surface of the electrode could make $\sigma_{\mathrm{V}}$ and $\sigma_{\mathrm{I}}$ much greater for the buffered solution of lower $\mathrm{pH}$ for which oxide is less stable.

After these analyses, the experimental data were transformed from the time domain into the frequency domain by fast Fourier transform. Power spectral density plots were obtained for potential, $\mathrm{PSD}_{\mathrm{V}}$, and current, $\mathrm{PSD}_{\mathrm{I}}$, and also spectral noise plots, where

$R_{\mathrm{sn}}(f)=\left[\frac{\operatorname{PSD}_{\mathrm{V}}(f)}{\operatorname{PSD}_{\mathrm{I}}(f)}\right]^{1 / 2}$

The spectral noise resistance $R_{\mathrm{sn}}^{\mathrm{o}}$ is defined as the dc limit of the spectral noise plot [17]

$R_{\mathrm{sn}}^{\mathrm{o}}=\lim _{f \rightarrow 0}\left[R_{\mathrm{sn}}(f)\right]$
Table 2

Electrochemical noise data in the frequency domain obtained in $0.1 \mathrm{M}$ $\mathrm{KCl}$ and in $0.1 \mathrm{M}$ acetate-buffered solution containing $0.1 \mathrm{M} \mathrm{KCl}$ at $\mathrm{pH}$ 5.4 and $\mathrm{pH} 4.3$

\begin{tabular}{rlll}
\hline $\begin{array}{l}\text { Immersion } \\
\text { time }(\min )\end{array}$ & $0.1 \mathrm{M} \mathrm{KCl}$ & $\begin{array}{l}0.1 \mathrm{M} \mathrm{KCl} / \mathrm{pH} \\
5.4 \mathrm{buffer}\end{array}$ & $\begin{array}{l}0.1 \mathrm{M} \mathrm{KCl} / \mathrm{pH} \\
4.3 \text { buffer }\end{array}$ \\
\hline$R_{\mathrm{sn}}^{\mathrm{o}}\left(\mathrm{k} \Omega \mathrm{cm}^{2}\right)$ & & & \\
60 & 11.9 & 29.1 & 13.6 \\
120 & 21.0 & 22.3 & 15.9 \\
180 & 29.0 & 26.0 & 16.5 \\
240 & 30.1 & 10.6 & 26.8 \\
$S_{\mathrm{V}}$ & & & \\
60 & -0.61 & -1.45 & -3.14 \\
120 & -0.36 & -1.05 & -3.05 \\
180 & -0.69 & -1.83 & -3.06 \\
240 & -0.62 & -0.91 & -3.05 \\
$S_{\mathrm{I}}$ & & & \\
60 & -0.04 & -0.20 & -1.38 \\
120 & -0.07 & 0.06 & -1.24 \\
180 & -0.17 & -0.45 & -1.25 \\
240 & 0.08 & -0.09 & -1.32 \\
$S_{R_{\mathrm{sn}}}$ & & & -0.87 \\
60 & -0.29 & -0.62 & -0.89 \\
120 & -0.15 & -0.55 & -0.90 \\
180 & -0.27 & -0.69 & \\
240 & -0.36 & -0.41 & \\
\hline
\end{tabular}

For aluminium in the various solutions studied here a dc limit was not observed, so that $R_{\mathrm{sn}}^{\mathrm{o}}$ was determined as the average of the ten data points at lowest frequencies.

The PSD plots and the spectral noise plots were fitted to:

$\log \mathrm{PSD}_{\mathrm{V}}=A_{\mathrm{V}}+S_{\mathrm{V}} \log f, \quad \log \mathrm{PSD}_{\mathrm{I}}=A_{\mathrm{I}}+S_{\mathrm{I}} \log f$,

$\log R_{\mathrm{sn}}=A_{R_{\mathrm{sn}}}+S_{R_{\mathrm{sn}}} \log f$

where $S_{\mathrm{V}}$ and $S_{\mathrm{I}}$ are the slopes of the potential and current PSD plots and $S_{R_{\mathrm{sn}}}$ is the slope of the spectral noise plot. It follows that the slopes of the PSD and $R_{\mathrm{sn}}$ plots are related

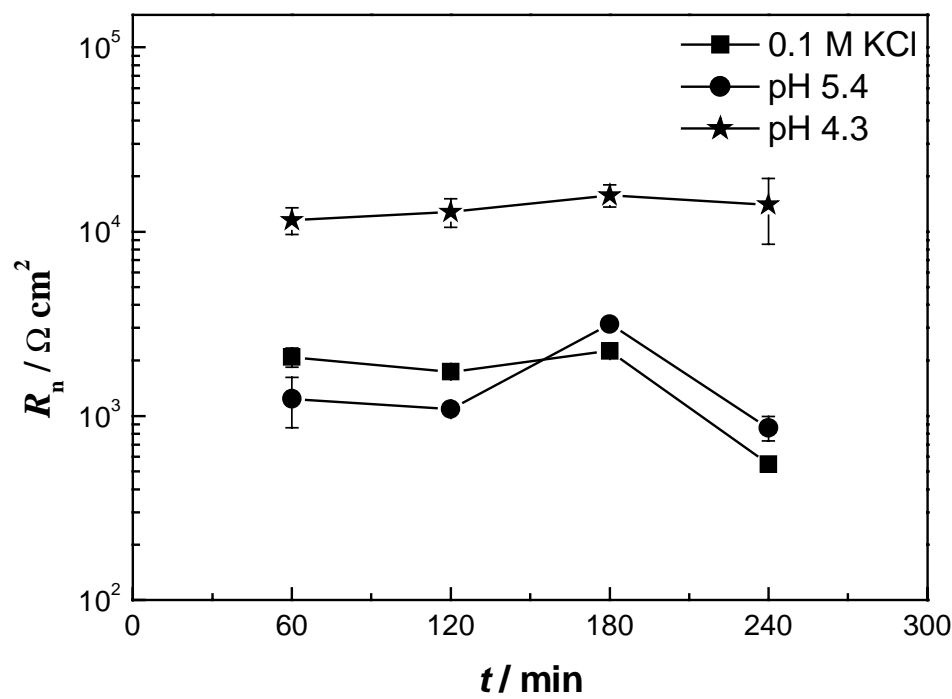

Fig. 4. Noise resistance obtained for $\mathrm{Al}$ in unbuffered $0.1 \mathrm{M} \mathrm{KCl}$ and $0.1 \mathrm{M}$ acetate buffer/0.1 M KCl at $\mathrm{pH} 5.4$ and 4.3 (average of three determinations). 
by the expression [17]:

$S_{R_{\mathrm{sn}}}=0.5\left(S_{\mathrm{V}}-S_{\mathrm{I}}\right)$

Typical examples of PSD plots are shown in Fig. 5.

The results obtained by fitting the slopes of the PSD plots are summarized in Table 2. Comparing the solutions, the slopes are greatest in the $\mathrm{pH} 4.3$ buffered solution. These slopes of potential are of the order of -3 for the PSD of potential at $\mathrm{pH} 4.3$, approximately -1.5 in $\mathrm{pH} 5.4$ buffer solution and approximately -0.6 in the unbuffered solution, showing significant dispersion in the latter two cases. The
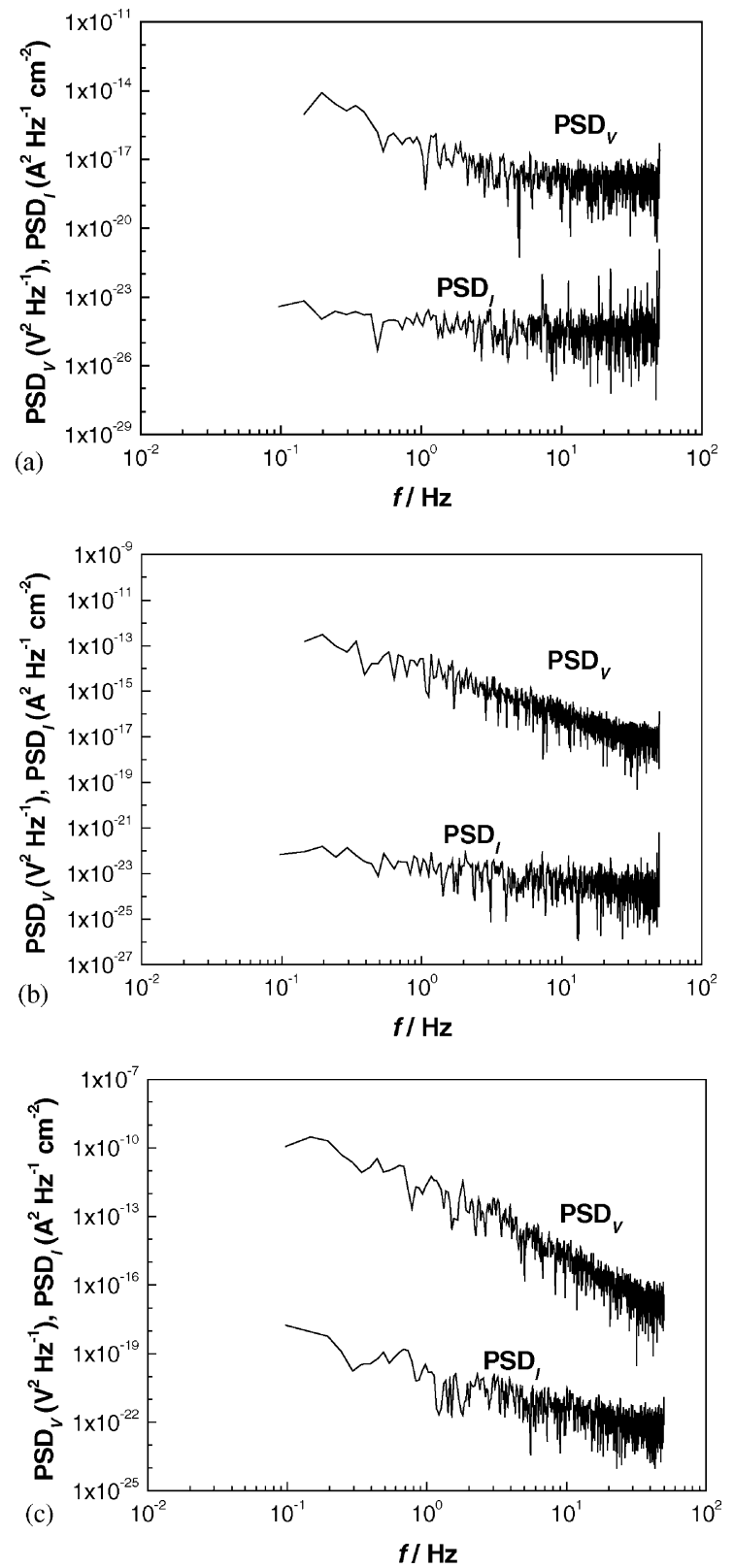

Fig. 5. PSD plots for $\mathrm{Al}$ immersed in (a) $0.1 \mathrm{M} \mathrm{KCl}$; (b) $0.1 \mathrm{M}$ acetate buffer/0.1 M KCl solution, $\mathrm{pH} 5.4$; (c) $0.1 \mathrm{M}$ acetate buffer/ $0.1 \mathrm{M} \mathrm{KCl}$ solution, $\mathrm{pH} 4.3$. slopes of current PSD are approximately -1.3 at $\mathrm{pH} 4.3$, -0.2 in the $\mathrm{pH} 5.4$ solution and -0.05 in the unbuffered solution. Again, a greater constancy in the slopes with increasing immersion time is seen in the $\mathrm{pH} 4.3$ solution. It has been suggested that the absolute magnitudes of the slopes of PSD are characteristic of the type of corrosion [34]. It can be inferred from the analysis in the frequency domain that the much more negative slope of current PSD in $\mathrm{pH}$ 4.3 buffered solution of $0.1 \mathrm{M} \mathrm{KCl}$, in which aluminium is
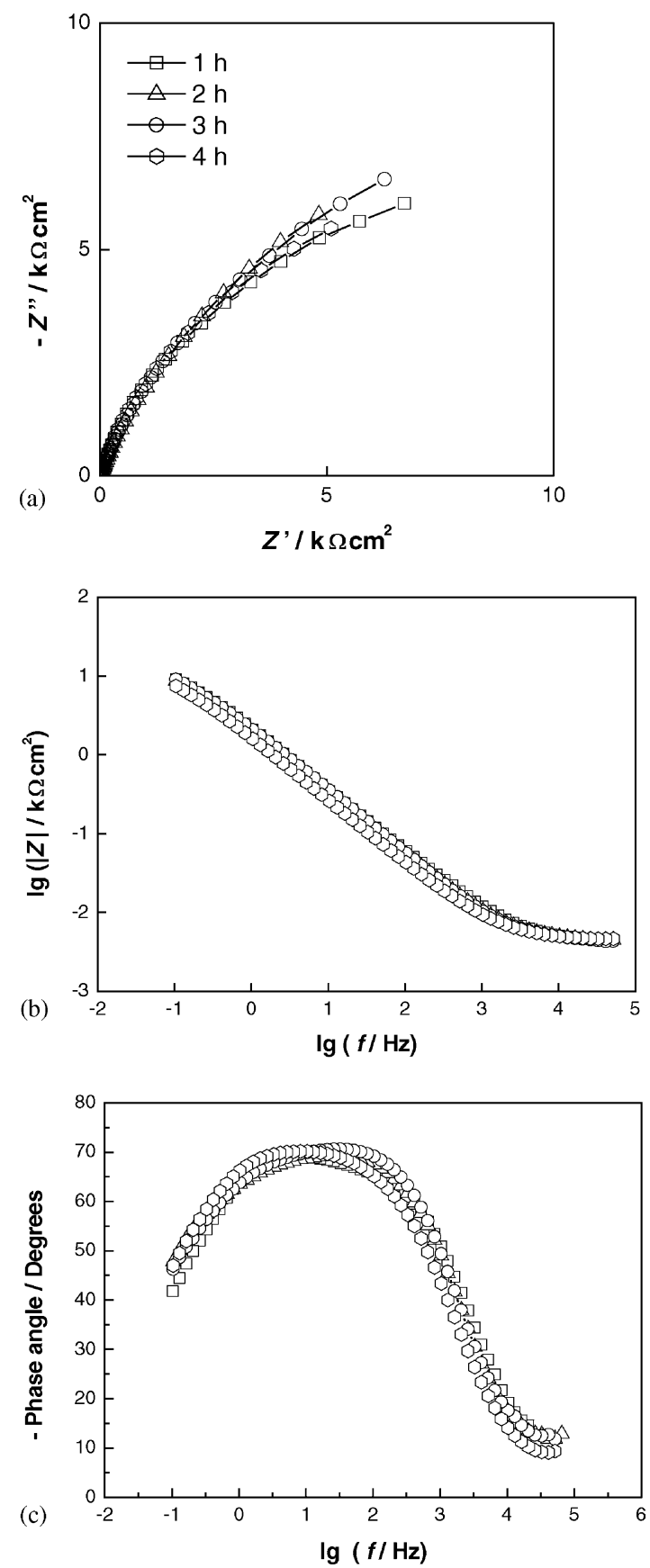

Fig. 6. Impedance spectra at open circuit potential of aluminium in $0.1 \mathrm{M} \mathrm{KCl}$ solution: (a) complex plane plots and corresponding; (b) Bode impedance magnitude; and (c) Bode phase angle plots. 
corroded more rapidly, is indicative of metastable pitting, as discussed earlier.

Several methods have been proposed for evaluating the degree of localised corrosion from electrochemical noise measurements, of these the 'characteristic frequency' being the most generally applicable [34]. This frequency is inversely proportional to the PSD of potential and is independent of the current noise. Examination of the PSD po-
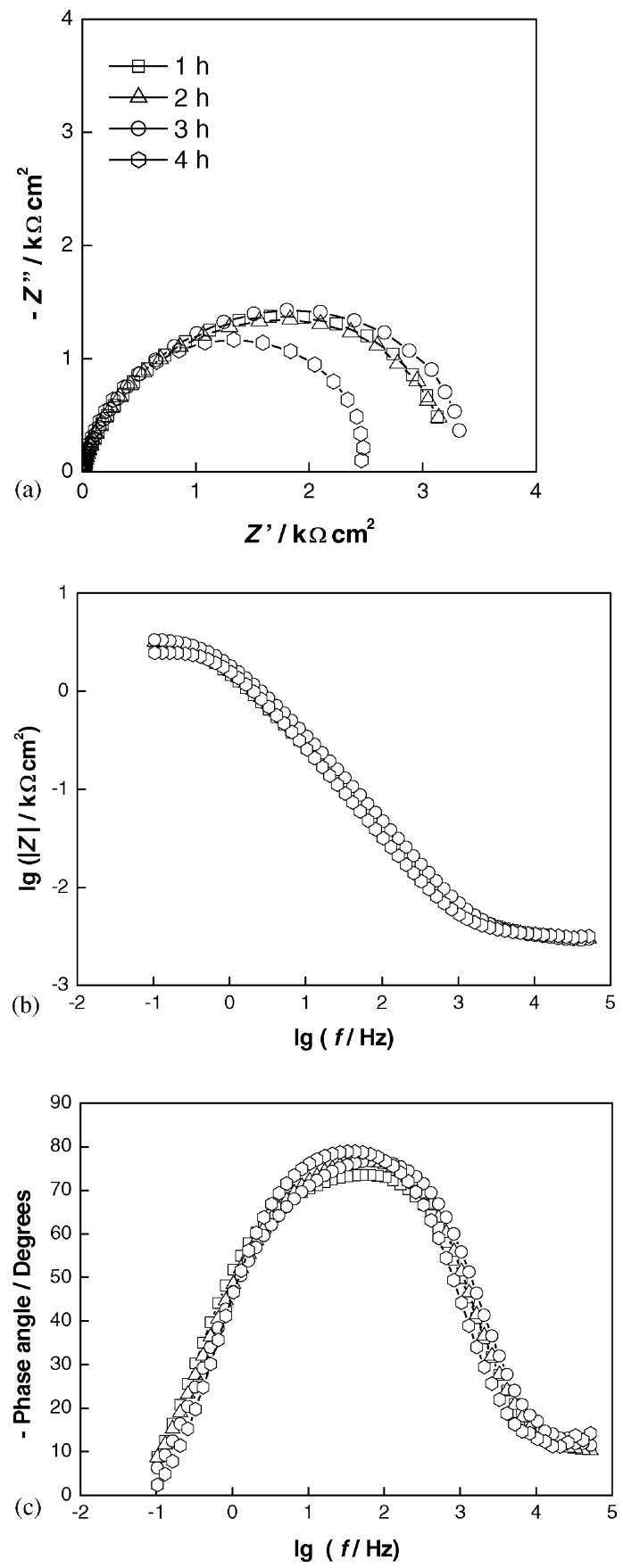

Fig. 7. Impedance spectra at open circuit potential of aluminium in $0.1 \mathrm{M}$ acetate buffer/0.1 M KCl solution, $\mathrm{pH}$ 5.4: (a) complex plane plots and corresponding; (b) Bode impedance magnitude; and (c) Bode phase angle plots. tential plots in Fig. 5 show a variation in the order $0.1 \mathrm{M}$ $\mathrm{KCl}<\mathrm{pH} 5.4$ buffered $\mathrm{KCl}<\mathrm{pH} 4.3$ buffered $\mathrm{KCl}$, although the difference between the latter two is not very large. The characteristic frequencies vary in the inverse order and the lower the frequency value the more localised the corrosion, i.e. greatest in the $\mathrm{pH} 4.3$ buffered solution. This is in agreement with visual observation and previous considerations above. Additionally, independent measurement of the
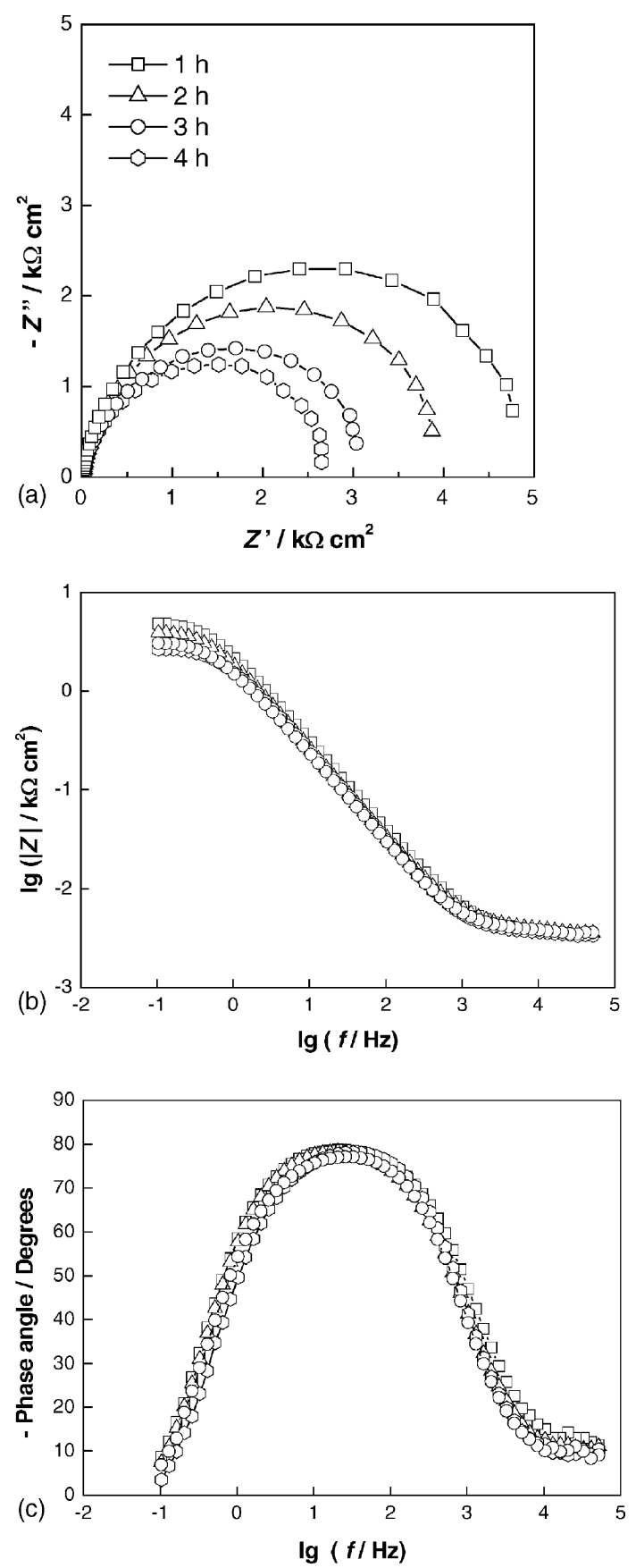

Fig. 8. Impedance spectra at open circuit potential of aluminium in $0.1 \mathrm{M}$ acetate buffer/0.1 M KCl solution, $\mathrm{pH}$ 4.3: (a) complex plane plots and corresponding; (b) Bode impedance magnitude; and (c) Bode phase angle plots. 
corrosion rate from Tafel plot analysis gave corrosion currents, of order of magnitude $\mu \mathrm{A} \mathrm{cm}^{-2}$, following the trend $0.1 \mathrm{M} \mathrm{KCl}<\mathrm{pH} 5.4$ buffered $\mathrm{KCl} \ll \mathrm{pH} 4.3$ buffered $\mathrm{KCl}$.

\subsection{Impedance measurements}

Impedance spectra of aluminium obtained for the different immersion times are illustrated in the plots in Figs. 6-8 for the three types of solution. Fitting of spectra was done by an equivalent electrical circuit which comprises the cell resistance, $R_{\Omega}$, in series with a constant phase element modelled as a capacitor

$\mathrm{CPE}=-\frac{1}{2}\left(C_{1} \mathrm{i} \omega\right)^{\alpha}$

$C_{1}$ representing the capacity of the passive oxide film, in parallel with a resistance, $R_{1}$, representing charge transfer. The value of $R_{\Omega}$ was around $4 \Omega \mathrm{cm}^{2}$ in all cases. The values of the other parameters obtained from equivalent circuit fitting are shown in Table 3.

There are clear differences between the spectra obtained in unbuffered solution of $0.1 \mathrm{M} \mathrm{KCl}$ and the two buffered solutions. The plots in the complex plane shows a semi-circle for aluminium in the acetate-buffered solutions, Figs. $7 \mathrm{a}$ and 8 a, i.e. the phase angle decreases drastically at low frequencies, Figs. $7 \mathrm{c}$ and $8 \mathrm{c}$. The largest values of the resistance $R_{1}$ were obtained for aluminium in unbuffered $0.1 \mathrm{M} \mathrm{KCl}$, which implies a lower rate of corrosion. In the two solutions with acetate buffer there is no significant difference in the values of $R_{1}$, so for these solutions the corrosion rate of aluminium from electrochemical impedance appears to be not very different. The values of $C_{1}$ are of the order of $1 \mu \mathrm{F} \mathrm{cm}^{-2}$, changing from $\sim 1 \mu \mathrm{F} \mathrm{cm}^{-2}$ in $0.1 \mathrm{M}$ $\mathrm{KCl}$ to $\sim 0.8 \mu \mathrm{F} \mathrm{cm}^{-2}$ on addition of acetate buffer at $\mathrm{pH}$ 5.4 (the same $\mathrm{pH}$ ) but return to close to $1 \mu \mathrm{F} \mathrm{cm}^{-2}$ at the

Table 3

Equivalent circuit fitting from impedance data in $0.1 \mathrm{M} \mathrm{KCl}$ and in $0.1 \mathrm{M}$ acetate-buffered solution containing $0.1 \mathrm{M} \mathrm{KCl}$ at $\mathrm{pH} 5.4$ and $\mathrm{pH} 4.3$

\begin{tabular}{ccll}
\hline $\begin{array}{l}\text { Immersion } \\
\text { time (min) }\end{array}$ & $0.1 \mathrm{M} \mathrm{KCl}$ & $\begin{array}{l}0.1 \mathrm{M} \mathrm{KCl} / \mathrm{pH} \\
5.4 \text { buffer }\end{array}$ & $\begin{array}{l}0.1 \mathrm{M} \mathrm{KCl} / \mathrm{pH} \\
4.3 \text { buffer }\end{array}$ \\
\hline$R_{1}\left(\mathrm{k} \Omega \mathrm{cm}^{2}\right)$ & & & \\
60 & 17.7 & 3.39 & 4.23 \\
120 & 18.9 & 4.18 & 4.18 \\
180 & 17.9 & 3.24 & 3.36 \\
240 & 15.2 & 3.08 & 3.36 \\
$C_{1}\left(\mu \mathrm{F} \mathrm{cm}^{-2}\right)$ & & & \\
60 & 0.97 & 1.00 & 0.92 \\
120 & 1.19 & 0.79 & 0.85 \\
180 & 1.31 & 0.74 & 0.97 \\
240 & 1.00 & 0.74 & 0.90 \\
$\alpha$ & & & \\
60 & 0.80 & 0.86 & 0.89 \\
120 & 0.78 & 0.86 & 0.91 \\
180 & 0.79 & 0.89 & 0.90 \\
240 & 0.81 & 0.91 & \\
\hline
\end{tabular}

lower $\mathrm{pH}$. However, the values of $\alpha$ are closest to 1 in the buffered solutions suggesting a smoother surface at the nanoscale. These results demonstrate the difficulties arising from use of just EIS which is unable to distinguish between the chemical composition of the interfacial region in different cases. Previous work showed that chloride ion content of the oxide film varies with $\mathrm{pH}$ [4] and that carboxylic acid molecules can weakly adsorb on the oxide surface [5]. The electrochemical noise data, however, are able to give some insight into the different behaviour in the two buffered solutions.
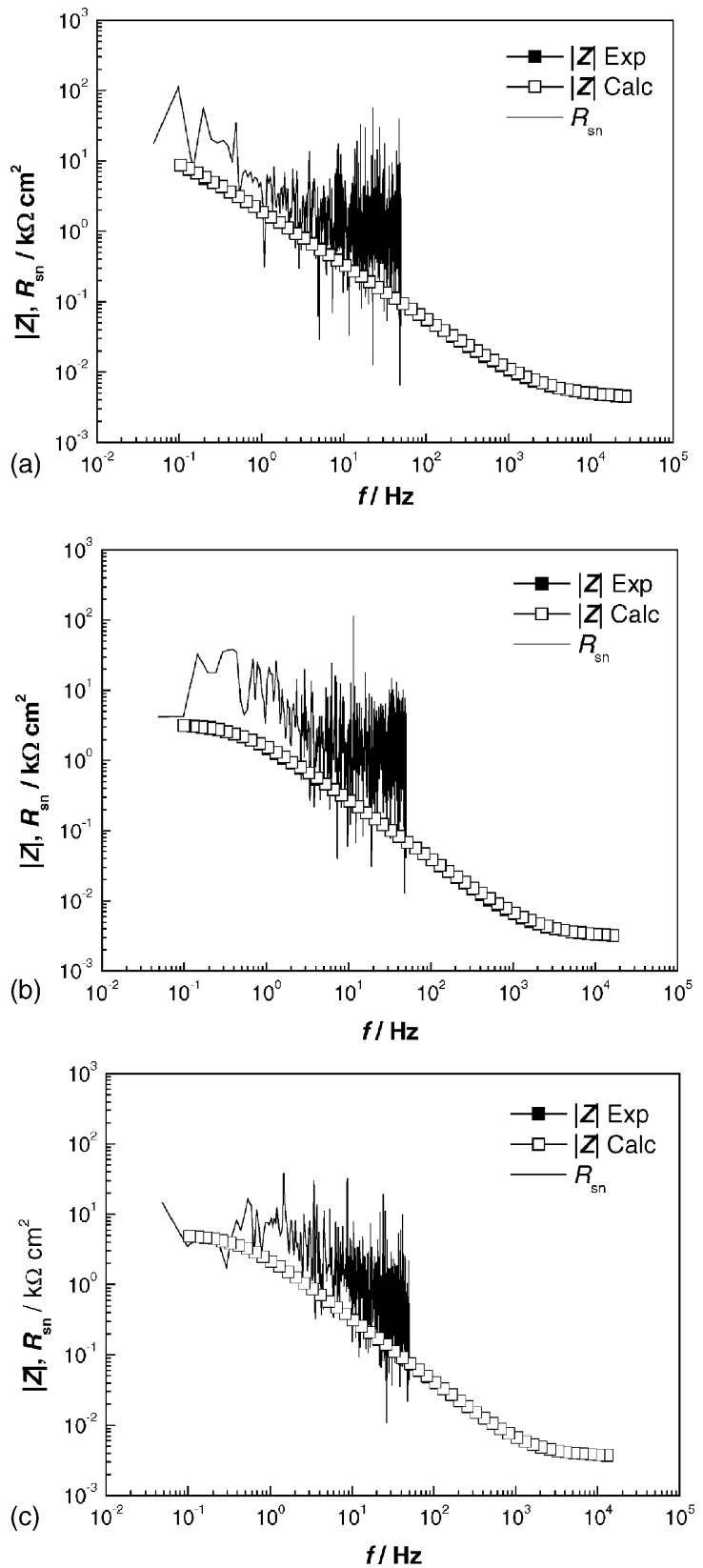

Fig. 9. Electrochemical noise and impedance data for $\mathrm{Al}$ after $1 \mathrm{~h}$ exposed in (a) $0.1 \mathrm{M} \mathrm{KCl}$; (b) $0.1 \mathrm{M}$ acetate buffer/ $0.1 \mathrm{M} \mathrm{KCl}$ solution, $\mathrm{pH} 5.4$ (c) $0.1 \mathrm{M}$ acetate buffer $/ 0.1 \mathrm{M} \mathrm{KCl}$ solution, $\mathrm{pH} 4.3$. 


\subsection{Comparison between EN and EIS}

A comparison of impedance modulus and spectral noise plots for $\mathrm{Al}$ exposed to $0.1 \mathrm{M} \mathrm{KCl}$ and the buffered solutions is shown in Fig. 9, after $1 \mathrm{~h}$ immersion. The results obtained are similar after longer immersion times. Often they have been found to be in agreement, for example, in the case of indium-ion activated aluminium corrosion in acidic chloride solution [11] and stainless steel in Ringer's solution [43]. A model has been developed based on localised corrosion which equates the noise impedance and electrochemical impedance [34]. In our case the values of $R_{\text {sn }}$ are higher than those of $|Z|$. Additionally, comparison of the values of $|Z|_{f \rightarrow 0}$ in Table 3 (equivalent to $R_{1}$ ) and $R_{\mathrm{sn}}^{\mathrm{o}}$ in Table 2 shows that $|Z|_{f \rightarrow 0}<R_{\mathrm{sn}}^{\mathrm{o}}$ for all three types of solution.

A possible explanation for this difference has to do with the experimental conditions. In the impedance instrumentation a fixed potential is imposed, equal to the open circuit potential at the beginning of the experiment, and any differences of local potential on the electrode surfaces are minimal, being corrected through feedback. However, under natural conditions there is no imposed external control and thus the local potential is able to vary more, in particular the formation of oxide following breakdown can be facilitated. In this way the resistance of the surface, which corresponds principally to that of the oxide film, can be larger. In the systems described in the literature demonstrating agreement there is generally either activation of the surface or the presence of an inhibitor. Both of these strategies could tend to make the corrosion process more uniform and the effect of localised corrosion less.

\section{Conclusions}

The behaviour of pure aluminium in $0.1 \mathrm{M} \mathrm{KCl}$ without and with acetate buffer at pH 5.4 and 4.3 has been studied. The analysis of electrochemical noise in the time domain suggests that the corrosion rate is lower in the more acid solution whereas frequency domain analysis shows clearly that aluminium is more rapidly corroded in this solution. A possible explanation is given by the presence of metastable pits on the surface of the electrode, which increases the instability and variation of the local potential. The electrochemical noise data can provide a useful diagnostic of such behaviour.

The analyses in the frequency domain are in good agreement with those obtained by EIS, allowing the conclusion that the presence of acetate buffer increases the corrosion rate of aluminium.

\section{Acknowledgements}

The financial support of ICEMS, Coimbra (Research Unit 103) is gratefully acknowledged.

\section{References}

[1] K. Nişancioğlu, H. Holtan, Electrochim. Acta 24 (1979) 1229.

[2] T. Hurlen, H. Lian, O.S. Ødegard, T. Valant, Electrochim. Acta 29 (1984) 579.

[3] H.J.W. Lenderink, M. van der Linden, J.H.W. de Wit, Electrochim. Acta 38 (1993) 1989.

[4] A. Kolics, A.S. Besing, P. Baradlai, R. Haasch, A. Wieckowski, J. Electrochem. Soc. 148 (2001) B251.

[5] F. Verpoort, T. Haemers, P. Roose, J.P. Maes, Appl. Spectr. 53 (1999) 1528.

[6] A.M. AlMayouf, Corr. Prev. Control 43 (1996) 68.

[7] J. Radošević, M. Kliškić, A.R. Despić, J. Appl. Electrochem. 22 (1992) 649

[8] L. Garrigues, N. Pebere, F. Dabosi, Electrochim. Acta 41 (1996) 1209.

[9] G. Burri, W. Luedi, O. Haas, J. Electrochem. Soc. 136 (1989) 267.

[10] J.-F. Equey, S. Müller, J. Desilvestro, O. Haas, J. Electrochem. Soc. 139 (1992) 1499

[11] C.B. Breslin, A.L. Rudd, Corros. Sci. 42 (2000) 1023.

[12] A. Aballe, M. Bethencourt, F.J. Botana, M. Marcos, Electrochim. Acta 44 (1999) 4805.

[13] M. Pagitsas, D. Sazou, J. Electroanal. Chem. 471 (1999) 132.

[14] J.C. Uruchurtu, J.L. Dawson, Corrosion 43 (1987) 19.

[15] J.W. Isaac, K.R. Hebert, J. Electrochem. Soc. 146 (1999) 502

[16] F. Mansfeld, H. Xiao, L.T. Han, C.C. Lee, Prog. Org. Coat. 30 (1997) 89

[17] F. Mansfeld, C.C. Lee, J. Electrochem. Soc. 144 (1997) 2068.

[18] H. Greisiger, T. Schauer, Prog. Org. Coat. 39 (2000) 31.

[19] D.J. Mills, S. Mabbutt, Prog. Org. Coat. 39 (2000) 41.

[20] R.J.K. Wood, J.A. Wharton, A.J. Speyer, K.S. Tan, Tribol. Int. 35 (2002) 631

[21] A. Nagiub, F. Mansfeld, Corros. Sci. 43 (2001) 2001.

[22] Y.J. Tan, S. Bailey, B. Kinsella, Corros. Sci. 44 (2002) 1277.

[23] A. Aballe, M. Bethencourt, F.J. Botana, M. Marcos, R. Osuna, Electrochim. Acta 47 (2002) 1415.

[24] F. Mansfeld, Z. Sun, C.H. Hsu, Electrochim. Acta 46 (2001) 3651.

[25] J. Smulko, K. Darowicki, A. Zieliński, Electrochim. Acta 47 (2002) 1297.

[26] G.P. Bierwagen, J. Electrochem. Soc. 141 (1994) L155.

[27] U. Bertocci, C. Gabrielli, F. Huet, M. Keddam, J. Electrochem. Soc. 144 (1997) 31.

[28] F. Mansfeld, H. Xiao, J. Electrochem. Soc. 141 (1994) 1403.

[29] H. Xiao, F. Mansfeld, J. Electrochem. Soc. 141 (1994) 2332.

[30] F. Mansfeld, Z. Sun, C.H. Hsu, A. Nagub, Corros. Sci. 43 (2001) 341.

[31] Y.F. Cheng, J.L. Luo, M. Wilmott, Electrochim. Acta 45 (2000) 1763.

[32] A. Bautista, U. Bertocci, F. Huet, J. Electrochem. Soc. 148 (2001) B412.

[33] A.M. Lowe, H. Eren, S.I. Bailey, Corros. Sci. 45 (2003) 941.

[34] R.A. Cottis, M.A.A. Al-Awadhi, H. Al-Mazeedi, S. Turgoose, Electrochim. Acta 46 (2001) 3665.

[35] J. Smulko, K. Darowicki, J. Electroanal. Chem. 545 (2003) 59.

[36] A. Aballe, F. Huet, J. Electrochem. Soc. 149 (2002) B89.

[37] S.E. Frers, M.M. Stefenel, C. Mayer, T. Chierchie, J. Appl. Electrochem. 20 (1990) 996.

[38] C.M.A. Brett, J. Appl. Electrochem. 20 (1990) 1000

[39] F. Mansfeld, H. Xiao, J. Electrochem. Soc. 140 (1993) 2205.

[40] D.J. Mills, G.P. Bierwagen, B.S. Skerry, D. Tallman, Mater. Perf. 34 (1995) 33

[41] U. Bertocci, C. Gabrielli, F. Huet, M. Keddam, P. Rousseau, J. Electrochem. Soc. 144 (1997) 37.

[42] R. Cottis, S. Turgoose, in: Corrosion Test Made Easy: Electrochemical Impedance and Noise, NACE, USA, 1999.

[43] C.C. Lee, F. Mansfeld, Corros. Sci. 40 (1998) 959. 